\title{
Modelagem de Ecossistemas de Software para Tecnologias Aplicadas a Cursos de Graduação EAD
}

\author{
Emanuel F. Coutinho ${ }^{1}$, Italo Santos ${ }^{2}$, Ernesto Trajano ${ }^{1}$ \\ ${ }^{1}$ UFC Virtual - Universidade Federal do Ceará (UFC) - CE - Brasil \\ ${ }^{2}$ Instituto de Ciências Matemáticas e de Computação \\ Universidade de São Paulo (ICMC/USP) - São Carlos, SP - Brasil
}

emanuel@virtual.ufc.br, italo.santos@usp.br, ernesto@virtual.ufc.br

\begin{abstract}
Resumo. A UAB é um sistema que oferece cursos de nível superior para a população com dificuldade de acesso à formação universitária, por meio da EAD. Diversos cursos de graduação semi-presenciais da UAB utilizam o AVA SOLAR, possuindo cada um diversas disciplinas em cidades distintas, com infraestruturas e tecnologias variadas. O SOLAR ECOS foi modelado para possibilitar uma visão geral de todo o ambiente que circunda o AVA SOLAR. O objetivo deste trabalho é mapear as tecnologias e tipos de recursos multimídia envolvidos nas disciplinas EAD oferecidas no AVA SOLAR.
\end{abstract}

\section{Introdução e Motivação}

A Universidade Aberta do Brasil (UAB) é um sistema integrado de universidades públicas que oferece cursos de nível superior para a população com dificuldade de acesso à formação universitária, por meio da Educação à Distância (EAD). A UAB propicia articulação, interação e efetivação de iniciativas que estimulam a parceria dos três níveis governamentais (federal, estadual e municipal) com universidades públicas e demais organizações interessadas, viabilizando mecanismos alternativos para fomento, implantação e execução de cursos de graduação. Atualmente, ela possui no estado do Ceará diversos cursos de graduação, com centenas de alunos atualmente matriculados em diversas cidades, com uma infraestrutura distribuída, espaços físicos cedidos por prefeituras, colégios e instituições federais, e uma plataforma central, o Ambiente Virtual de Aprendizagem (AVA) SOLAR, e uma série de profissionais ligados à EAD.

A Universidade Federal do Ceará (UFC) possui diversos cursos de graduação presenciais e semi-presenciais que utilizam o AVA SOLAR. O SOLAR é um ambiente web cujo modelo de participação é orientado ao professor e ao aluno, possibilitando a publicação de cursos e interação com os mesmos. Também existe uma versão móvel do AVA, porém bem mais simplificada. Seu ECOS foi modelado em [Coutinho et al. 2017].

Cada curso de graduação possui diversas disciplinas em cidades ou polos distintos. Tais polos são diferentes, possuindo infraestruturas variadas. Nem todas as tecnologias de hardware e software necessárias aos cursos estão disponíveis. Além disso, os professores ou tutores podem utilizar diferentes metodologias e aplicações em suas aulas. Nesse sentido, a quantidade de tecnologias utilizada é bem variada, possibilitando novas oportunidades de pesquisa desenvolvimento de aplicações.

Um ECOS pode consistir de um conjunto de atores agindo como uma unidade que interage com um mercado distribuído entre software e serviços, juntamente com as 
relações entre estas entidades [Jansen et al. 2009]. Tais relações são frequentemente apoiadas por uma plataforma tecnológica ou por um mercado comum e realizadas pela troca de informação, recursos e artefatos. Nesse contexto, conhecer o ECOS do SOLAR e o que está ao seu redor de tecnologias, não necessariamente vinculados fisicamente a ele, possibilitaria um melhor planejamento e acompanhamento das atividades no AVA.

O objetivo deste trabalho é propor uma pesquisa para o mapeamento das disciplinas EAD oferecidas no AVA SOLAR, suas tecnologias e seus recursos multimídia, e assim modelar um ECOS mais completo e atual, orientado às disciplinas da UAB.

\section{Proposta de Pesquisa}

A pesquisa consiste no mapeamento das disciplinas EAD oferecidas no AVA SOLAR, as ferramentas (software ou hardware) e os recursos multimídia utilizados nas aulas de acordo com os cursos. Para isso, uma série de etapas devem ser executadas:

- Identificar Disciplinas: Muitas disciplinas existem na UAB, ocorrendo ao mesmo tempo e em locais diferentes. Ao se identificar essa lista, pode-se estimar a abrangência que o ECOS SOLAR atinge. Um exemplo é a construção de uma rede sociotécnica.

- Identificar Tecnologias Utilizadas: A mesma disciplina pode utilizar diferentes ferramentas e recursos, seja de hardware ou de software, e de fornecedores diversos. Isto depende muito do local onde a disciplna está ocorrendo, da infraestrutura disponível, das condições de acesso à rede, e dos profissionais envolvidos.

- Identificar Recursos Multimídia: Por recursos multimídia entende-se material produzido e disponibilizado nas aulas das disciplinas que utilizem imagem, som, vídeo e animações. Para a produção desses materiais, são necessários diversos tipos de softwares. Essa etapa consiste em mapear o tipo de material e como foi produzido.

- Modelar ECOS: Gerar modelos de ECOS da UAB relacionado ao softwares utilizados na elaboração das aulas e produção de materiais multimídia. Esse modelo pode ser por polo ou toda UAB. Possivelmente atualizar o ECOS SOLAR [Coutinho et al. 2017] atualmente construído ou delimitar novas fronteiras do ECOS.

\section{Conclusão}

Este trabalho está em um estágio inicial. Espera-se com essa pesquisa que se possa ter uma visão da importância e impacto das tecnologias para as aulas EAD para a comunidade de desenvolvimento e sociedade. Além disso, com uma visão mais global de um ECOS, que seja possível analisar riscos envolvidos no ambiente e melhor planejar as atividades para que elas possam refletir uma maior qualidade no ensino.

\section{Referências}

Coutinho, E. F., Santos, I., e Bezerra, C. I. M. (2017). A software ecosystem for a virtual learning environment: Solar seco. In 2017 IEEE/ACM Joint 5th International Workshop on Software Engineering for Systems-of-Systems and 11th Workshop on Distributed Software Development, Software Ecosystems and Systems-of-Systems (JSOS).

Jansen, S., Brinkkemper, S., e Finkelstein, A. (2009). Business network management as a survival strategy: A tale of two software ecosystems. In Proceedings of the First International Workshop on Software Ecosystems, 11th International Conference on Software Reuse, pages 34-48. 